\title{
Dynamic thinking and complexity: considerations for health promotion
}

\author{
Agnė Slapšinskaitė ${ }^{1}$, Justina Vaitkevičiūtė ${ }^{2}$, Monika Grincaité ${ }^{3}$, Lukas Galkus ${ }^{4}$, \\ Asta Raskiliené ${ }^{5}$, Laura Luukkonen', Alfonsas Vainoras ${ }^{7}$ \\ $1,2,3,4,5,7$ Health Research Institute, Faculty of Public Health, Medical Academy, Lithuanian University of \\ Health Sciences, Kaunas, Lithuania \\ ${ }^{1}$ Department of Sports Medicine, Faculty of Nursing, Medical Academy, Lithuanian University of Health \\ Sciences, Kaunas, Lithuania \\ ${ }^{6}$ City of Turku, Turku, Finland \\ ${ }^{1}$ Corresponding author \\ E-mail: ${ }^{1}$ agne.slapsinskaite@lsmuni.lt, ${ }^{2}$ justina.vaitkeviciute@lsmuni.lt, ${ }^{3}$ monika.grincaite@lsmuni.lt, \\ 4lukas.galkus@lsmuni.lt, ${ }^{5}$ asta.raskiliene@lsmuni.lt, ${ }^{6}$ laura.luukkonen@turku.fi, ${ }^{7}$ alfavain@gmail.com \\ Received 4 June 2020; received in revised form 18 June 2020; accepted 23 June 2020 \\ DOI https://doi.org/10.21595/chs.2020.21514 \\ Check for updates \\ Copyright (C) 2020 Agne Slapšinskaitè, et al. This is an open access article distributed under the Creative Commons Attribution License, \\ which permits unrestricted use, distribution, and reproduction in any medium, provided the original work is properly cited.
}

\begin{abstract}
The aim of this perspective paper is to present a new and unique viewpoint on existing challenges, fundamental concepts, and prevalent notions on health promotion. Paper focuses on possible implications of a newly implemented Healthy Boost project. We further discuss existing health promotion interventions from the standpoint of dynamic complex systems while exploring the need to foster the cooperation component. Disclosure of these relationships and their utilization for structure optimization and evolution of functional possibilities, through the use of the dynamic characteristics of determined chaos at various levels, demonstrate plausible opportunities for the effective implementation of health promotion projects. The topic of health promotion effectiveness is of societal concern to a wider audience and to the scholarly community in general. Consequently, this perspective piece advances the future direction of application of Healthy Boost project within complexity framework.
\end{abstract}

Keywords: health promotion, cooperation, complex systems, heath, interventions.

\section{Introduction}

\subsection{Health promotion interventions: existing approach}

\subsubsection{Development of health promotion definition}

World Health Organization (WHO) in 1946 defined "Health as a state of complete physical, mental and social wellbeing and not merely the absence of disease or infirmity" therefore since establishing a holistic view on health $[1,2]$. Good health is seen as a result of the complex processes, achieved by collective individual and communal efforts. More so, participation and collaborative actions of the individuals, society, policymakers, environmental (i.e., urban development) and social interventions in a cross-sectoral approach became a crucial component for health.

It took almost 40 years to adopt health definition after a more holistic perspective on health was introduced in the first international conference [3]. Herein both the Ottawa Charter for action to achieve Health for All by 2000 and the definition of health promotion were presented $[3,4]$. According to the definition "Health promotion enables people to increase control over their own health. It covers a wide range of social and environmental interventions that are designed to benefit and protect individual people's health and quality of life by addressing and preventing the root causes of ill health, not just focusing on treatment and cure" [4]. Thus, three core strategic principles for health promotion were declared: advocacy for health, people enablement (i.e., allowing all people to achieve health equity), and mediation between the different sectors [3, 4]. 
Previous strategies were supported by five priority action areas, which were: the development of healthy public policy, the creation of supportive environments, strengthening of community action, development of personal skills, and reorienting health services [4]. Therefore, Ottawa Charter formed the basis of guidance and inspiration for health promotion for the next few decades.

Further, international community continued to develop concepts of health promotion and highlighting the importance of active political commitment and multiple stakeholders' involvement. These aspects were discussed in Adelaide recommendations of healthy public policy action [5], the Jakarta Declaration on Health Promotion into the $21^{\text {st }}$ Century, Bangkok charter and the 7-9th Global conferences of health promotion. It is evident that the support from the international community to engage various stakeholders and to include health aspect in all policies has been present for a while. In order to ensure adequate health promotion timely and effective interventions should be installed. An intervention can be seen as a combination of program elements or strategies designed to produce behaviour changes or improve health status among individuals or an entire society. Interventions may include educational programs, new or stronger policies, improvements in urban development, or a single health promotion campaign [5]. Interventions carried out in collaboration between different sectors can help persons to achieve desirable health status. However, the effectiveness of interventions is highly dependent on circumstances, personalities, and coincidences as well as resources together with a relation of functioning regulatory institutions (i.e., management-labour) [6]. Finally, the success of the intervention highly depends on the policy support, the involvement of different stakeholders, and individuals' participation [7].

The aim of this perspective paper is to present a new and unique viewpoint on existing challenges, fundamental concepts, and prevalent notions on health promotion. Paper focuses on possible implications of a newly implemented Healthy Boost project.

\subsubsection{Why it is relevant? How to enhance the health of citizens?}

According to WHO, two-thirds of the European Region population live in urban areas [8]. By 2030 the number is expected to overreach $80 \%$ of the European population. Although urban environment may offer many advantages, it also embraces many health risks [9]. Health challenges and issues are mainly related to citizens' violence, unhealthy environment (i.e., lack of green spaces, air pollution), non-communicable diseases (i.e., diabetes), low physical activity, unhealthy eating habits and, harmful use of psychoactive substance (i.e., tobacco). Thus, due to increased mass marketing, availability of unhealthy food choices and increased transport direct effects on lifestyle and health are more noticed among individual living in urban areas $[9,10]$. Therefore, urbanized areas face rising inequalities among different social groups [11] that is reflected through poverty growth, wealth, and homelessness [12].

Despite obvious benefits, there have been number of significant risks related to urbanization. The most common causes of premature death attributable to outdoor air pollution are ischaemic heart disease and stroke (72\%), chronic obstructive pulmonary disease and lung cancer. The economic cost of deaths and diseases from air pollution in the WHO European Region amounted to US\$ 1.6 trillion [13]. Urban risk factor after pollution is traffic noise. Over one million healthy life-years were lost per annum in western European countries from traffic-related noise [14]. In 2013, road traffic crashes killed 85000 people in the WHO European Region. In the group aged 5-29 years it was the leading cause of death [15]. Another challenge associated with individuals' health is type 2 diabetes (referred as biggest epidemic in human history). In 2013 more than 82 million people suffered from diabetes, and by 2035 this number is expected reach 595 million [16]. Residing in European cities can further be a risk factor for mood and anxiety disorders, psychotic disorders, and substance abuse, particularly in vulnerable society groups $[12,17,18]$.

Once addressing these problems, the holistic approach with the involvement of various sectors in community interventions is greatly encouraged. Urban societies' health and wellbeing is shaped by national and global trends, as well as municipal determinants [19]. In order to ensure health 
and wellbeing, it is highly important to draw attention to individuals health in urban areas, and to involve not only the individual, national, foreign levels, but also international organizations, local business in a shared effort to put health at the heart of urban policy [9]. Therefore, the enhancement of the cooperation between different departments (e.g. city administration, health, environmental, social, etc.) and sectors (e.g. non-governmental organizations, small and medium-sized enterprises, etc.) within the city is inevitable priority.

\subsubsection{The need to shift cooperation in health promotion: complexity of the problem}

One of the main reasons why ongoing health programs and interventions do not always achieve satisfying results relates to public perception towards public health. Public health together with health care sectors are widely seen as the only ones responsible for level of society health. The society health and wellbeing are dependent from the whole environment it interacts with. Thus, the involvement of all sectors and coherent cross-sectoral cooperation is important for the common goal - better health of all. Cross-sectoral cooperation in all sectors could contribute to even greater success.

The positive impact of cross-sectoral cooperation on the society health is supported by various scientific studies. To illustrate, USA informal partnerships between broad range of organizations in health care and other sectors improved quality of services provided to elderly, lowered hospital readmission rates, and reduced preventable health care and spending [20]. Further, communitybased initiatives like SCOPE (with involvement of local government, health, schools, recreation, local media, early childhood, community services) have proven to be effective to fight childhood obesity [21]. Organization "HealthPartners" worked with schools, foundations, non-profits, state and local governments, and other organizations in multisector health initiatives, to promote healthy eating in schools, reduce stigma of mental illness, improve end-of-life decision making, and strengthen an inner-city neighborhood [22]. These are just the few examples of the importance of cross-sectoral cooperation once dealing with complex problem that require a holistic approach.

Cooperation is the skill that is required and should be fostered by city residents especially when trying to maintain and improve the level of health. The following analysis of healthy city definition which is seen as "continually creating and improving physical and social environments and expanding community resources which enable people to mutually support each other in performing all the functions of life and developing to their maximum potential" [23] perfectly illustrates the importance of cooperation. Being a Healthy City depends not on the current health infrastructure, but rather upon a commitment to improve a city's urban environment and willingness to forge the necessary connections, interactions in political, economic, and social arenas [24]. Cross-sectoral cooperation between and among individual, national and foreign levels in the connections with political, economic and social arenas can provide a collaborative effort in which partners from different societal sectors (i.e., public, private, and non-profit) pool their resources to provide joint solutions and collective effort to reach common benefit in the area of health. Addressing the common problems and complex challenges such as aforementioned urban health challenges the main aim is to improve the capacities of local authorities and to enable individuals to actively be involved in health enhancement through cross-sectoral cooperation.

\subsubsection{Complexity theory: how it can make health promotion more effective?}

Today's health care and promotion environments are becoming increasingly complex. As scientists work more on complex systems, they gain deeper understanding of their defining properties. A complex system is characterized by a highly connected network of entities (i.e., physical objects, people, or people groups) from which emerges higher order behaviour [25]. The complexity paradigm can stand as disciplinary matrix in line with its implicit stances and basic values. Complexity itself stands as a potential solution that can add coherence and direction to this emerging field in health promotion practice. As previously presented the relevance of the 
complexity paradigm lies primarily at the epistemological and methodological/theoretical levels [5].

The function of health promotion in society and its realization must contain a certain level of complexity that would be capable to perform health promotion function. Properties of complex systems are widely presented by Yaneer Bar Yam (New England Complexity System Institute (NECSI, MIT) [26] and Michael Beranger (MIT) [27]. Main properties that may determine the requirements needed to accomplish realization of "health promotion" functionality in society are: 1) interconnections between the system elements (also called agents) follow non-linear dynamics, 2) organizes its functions on the basis of deterministic chaos, 3) contains fractal levels, 4) evolves only when harmony or coherence between its elements is present, 5) involves an interplay between cooperation and competition [26,27].

The understanding of critical systems interconnections is crucial as it drives the evolution of health promotion functionality. For example, at each fractal level, there is a regulatory body (administration in any level of health promotion activity) that plausibly initiates some activity in the field of health promotion, financial resources are provided to support such an initiative, and a real institution such as a company emerges that takes this initiative to fulfil. That is because a small change in the areas of management, financing or implementation provoke all other complex system components instantaneously to review their capabilities and adapt. The functionality of the whole system and its changes to the possible transformations of the initial conditions is presented in Fig. 1. In complex system evolution few of necessary conditions should be fulfilled once coherence between elements is maintained. Having said this, the among many important features in realization of health promotion projects is good cooperation.

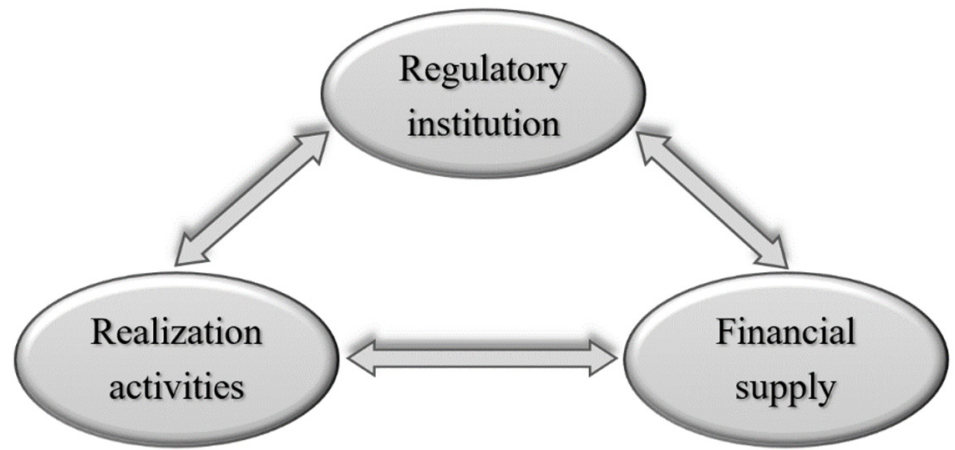

Fig. 1. Basic complexity structure needed for realisation of any health promotion initiative

The relationships and interconnectedness between the elements included into complex system change over time. Specifically, for this over-time change systems elements use a certain dynamic equilibrium that can be defined as a state of deterministic chaos. This is exhibited by a wide variety of systems governed by nonlinear dynamic laws [28]. The state of deterministic chaos is capable to characterize the whole dynamics of the system that can be specifically defined as a certain formed attractor. "Attractor solutions" to which the system evolves for a wide range of initial conditions [29]. The order can be defined by attractors that is hierarchy formed at each level of the system. Such regularities can be seen starting from the national level, later moving to separate administrative units, regions, cities, municipalities, and individual personal level.

One of the major causes for poor public health is inadequate financial resources [30]. Funding is widely presented as the main reason why the health promotion system does not work perfectly. Although health promotion interventions are often underfunded, surveys show that health promotion of older adults in Europe is financed by public funds, also by private funds and local municipalities. Further, it is observed that problems are faced when there is a lack of information on funding mechanisms, resource allocation, responsible institutions, executors [31]. The reason for this may be that lot of sectors are potentially involved in health promotion for older people: 
(1) health sector, (2) social sector (3) central and local government, (4) workplace/ enterprises/employers, (5) NGOs and voluntary organisations, (6) sport and education, (7) media [32]. Coherent cross-sectoral cooperation between different sectors of health promotion system could help to address global challenges such as aging population.

Scientific literature presents that effective health program implementation requires an adequate funding, resources, and support from all levels [33]. Therefore, a long-term commitment from government, non-governmental sector, healthcare, public and educational systems will contribute to ensure desirable outcomes of health promotion programs in the future. We further state of efficient functionality requires good political leadership, properly functioning regulatory institutions, coherence, and efficient cooperation between all three parts of the system as presented in Fig. 1.

However, the opposite situation may also occur when the health promotion system is well managed by regulatory institution but lacks financial resources and motivation for those targeted for health promotion. For instance, in Poland, health promotion project for schools' staff was evaluated. The project leaders were found to be confronted with insufficient financial resources and difficulties in motivating school employees to undertake health-promotion activities [34]. Organizational constraints may also cause counterproductive reactions. For example, the physical activity programs for patients or individuals with non-communicable diseases at risk in Grand-Duchy of Luxembourg. The program evaluation showed that, the low rate of participating was related to a lack of organizational constraints and dissemination of information. Most of the potential participants were not aware of the existence of such physical activity groups. Public health action initiated by these groups should be strengthened with a better structuration [35].

The implementation aspect of health promotion activities is particularly important. For example, managing professional burnout among healthcare professionals. Sometimes such programs do not require significant financial resources, but it is important that leaders understand the importance of health promotion intervention targeted to reduction of burnout syndrome [36]. The functioning of such system is crucial for the healthcare system and for the patient care quality. Well-functioning health promotion initiatives, which are relatively cheap, can have a significant impact on the health of the population. Specifically, in European cities switching from car trips to bicycle trips reduces pollution and prevents road traffic fatalities. Otero and colleagues have assessed that if all car trips would be replaced by bike-sharing systems trips, 73.25 deaths could be avoided each year (225 million Euros saving) in the twelve Europe cities (Barcelona, Brussels, Hamburg, Lille, Lyon, Madrid, Milan, Paris, Seville, Toulouse, Valencia and Warsaw) [37].

Dynamic nature of a complex system assumes that its elements are constantly modifying their rules for interaction. Each element is facing novel surroundings due to the changing behaviour of the other elements that provide stimuli at any level. The aggregate behaviour of the system continues to evolve due to simultaneous interactions among elements [38, 39]. The interconnectedness of the elements within a system ensures that any stimuli from inside and/or outside the system triggers changes within the system, between the system and the outside environment, and back to the system [40]. Due to the dynamic nature and constant action and reaction to what "others" are doing, nothing is static, and dynamic systems constantly change and evolve, presenting a "moving target" [38].

Realizing that all the interconnections in society maintain various functionality levels that can be seen as dynamic systems, more precisely, systems of determined chaos. We further can postulate that at every other historical moment they can modify, adapt to new challenges and existing limitations. What it entails for the problem at hand? Is it a complete ignorance of the problem, or is it a new use of communication technologies to facilitate, strengthen, evolve, discover new qualities and opportunities to realize and adapt to existing aspirations of health promotion? 


\subsection{Dynamic nature: health and cities}

Word dynamics holds a variety of meanings. A dynamic scenario in health would be the best to represent as a time-varying scenario. Specifically, health is containing that dynamic perspective as it can be seen as an adaptive state unique to each person [41]. To make this idea more concrete, it should firstly be referred to variables and time courses. In nonlinear dynamical systems, the fixed point, and their stability organize the ensemble of all solutions within dynamical systems. If we consider each individual as a unique biological system, health states must emerge from physiological network structures and personal behaviours [41].

The flow can be thought of as a mapping form all initial conditions to the states solutions that lead those initial conditions to at a given time. The dynamic systems are aimed at characterizing the flow of the dynamical system rather than analytical solving specific equations [42]. Further, dynamic theory attracted the idea that the urban environment (i.e., city) may act as one contribution to a behavioural dynamic, skills may be softly assembled in different environments, accounting for the context effects. Providing an understanding of multi-causality in development that may emerge from the joint effect of multiple factors rather than depend on a single, critical factor alone [42].

Different short and long-term responses enable the system to cope and adapt to change in order to sustain its function and health [43]. That is of a particular interest in the understanding of the most effective public health interventions and its application in the cities for the individuals. The dominance of feedback loops shifts over time (i.e. one feedback loop loses strength while another gains), and dynamic complex system behaviour arises due to the shifts in strength of different feedback loops within the system [44]. Health is an emergent state that arises from hierarchical network interactions between an individual's external urban environment and internal physiology [41]. We intend to better understand the dynamics of these interactions to boost the health through various interventions applied within the public health framework.

\subsubsection{Defining dynamic urban environment interactions}

From dynamical perspective several political, economic, social, and infrastructural characteristics of city networks interact. Cities are becoming something else as well: engines of health that are both public and environmental, sanitary, and sustainable [25]. Polycentric governance networks contribute to urban resilience depending upon their adaptive capacity to (1) address the essential interdependence of demographic, economic, social, built, and ecological challenges and solutions that cities face; (2) plan for the long term within the context of uncertainty and change; and (3) adjust governance structures to meet changing needs [25]. Development is about structural change on many scales, from the patterns of thought and habits of the individuals, to the patterns of intra and inter-regional and world health situation and economy "socio-economic" types. The fact that cities are complex adaptive systems is manifest in the definition provided in: Systems whose components interact in ways that cause the system to adjust or "adapt" in response to changes in conditions [45]. This is a simple consequence of interactions and feedbacks.

We further state that temporal dynamics and interactions are just as important as spatial pattern since none of these social patterns are stably fixed in time. Cities express general phenomena such as the division of labour and knowledge, epidemics of diseases and information, spatial topology, and densification as well as migration that can be better understand through the application of dynamical system theory [46]. Further, better understanding of dynamical perspective especially once different types of scientists/specialist interact in concerning with the same problems (i.e., active transportation and health) is of special importance. Specifically, urban dynamic couple physical, social, and ecological sub-systems which, due to interdependences, resist unilateral solutions and call for a new approach to conceptualizing and finding solutions [47]. In city a system renders a set of connected interdependent elements as a web of interrelationships, 
producing a dynamical pattern of behaviour seen by someone as generating a purpose in specific area within city such as the public health intervention.

Cities were modelled as dynamic systems, in nature journal since 1971, from then it is known that greater insights into the structure of the cities can be achieved using a dynamic rather than a static approach [48]. Understanding of the origin, and evolution of patterns settlement, urban growth and structure can be studied through this dynamic approach. The autonomy of the components (actors), and their ability to add and subtract energy to their won wishes is what makes prediction impossible unless we can find some fixed rules of the behaviour, or some fixed goals. This could help to derive the plausible behaviour direction of the system.

\subsubsection{Cities as complex, dynamic adaptive systems that implement health interventions}

Health interventions require approaches that perceive cities as complex, dynamic, and adaptive systems that depend upon interrelated ecosystem services at local, regional, and global scales. As examined in the beginning, individuals have relocated from the countryside to towns and cities during the past 50 years [45]. An important consequence of these trends in urban growth is that cities have become the dominant global human habitat of this century. This reality has important consequences for social and ecological systems at global, regional, and local scales, as well as for natural resource organizations attempting to integrate ecological function with human desires, behaviours, health, and quality of life. We are only beginning to understand the dynamics of human responses to variation of these services. Understanding these dynamics is crucial for understanding the push-pull drivers of urban health ecosystems and their resilience over time [49].

The nested hierarchy of structure that emerges both in city as health intervention in isolation is not necessarily "optimal" in any simple way, because there are a multiplicity of subjectivities and intentions, fed by a web of imperfect information. Creativity, and adaptive response are therefore powered by the degree of heterogeneity of the society, and their microscopic diversity as well as the variety of the involved agents of the interventions (i.e., local authorities, small medium enterprises, NGO and individuals to mentions some of them). Successful cooperation in the implementation of the health intervention in the city should lead to a community of interlocking behaviours, expressing increasing cooperation and complementarity, not competition. An economy is a "complex" of different activities that to some extent "fit together" and need each other that is a prerequisite for the health intervention within the city.

\subsubsection{Individuals as complex, dynamic adaptive systems: the smallest agent of health promotion}

In the paper, we also offer a dynamic and integrative approach for individuals as the main target of the public health interventions. From a broader perspective once analysing individuals it is presented that personality itself is dynamical and combines within-person and between-person differences [50]. To say that, dynamical understanding may contribute towards individual's involvement in the health promotion activities. Consequently, investing time to really know baseline of personality may be crucial. Especially because baseline reflects the stable set point around which one's individual states demonstrated personal variability (i.e., fluctuations). This is important to understand that individual states fluctuate across time and situations (never keeps the same), but this happens within the individual attractor force, pertaining to the swiftness with which deviations of one's baseline are pulled back to the baseline [50]. This means that health promotion is making a shift in the traditional, more stable behaviour of individual, however once the perturbation (i.e., intervention of health promotion) is removed, the individual is more plausibly to get back to its baseline state of behaviour that is possibly less healthy. This dynamic approach to individual's personality offers a consensual paradigm of personality with the potential to advance our understanding and knowledge of individual differences and it changed the understanding of the challenges that emerge once changing behaviour and lifestyle. 
Consequently, individual personality attractor strength represents how fast one returns to his/her baseline after they deviated from it (i.e., health intervention). Attractor strength plays an important role in the personality system as it bridges stability (i.e., returning to one's baseline) and change (i.e., moving away from one's baseline). In fact, thanks to the existence of such a self--regulatory component, the system can balance stability of the baseline with constant perturbations of the system. Attractor strength is most likely to be trait-specific meaning that an individual can have a strong attractor for one trait, but a weak attractor for another trait [50]. Fast return to a highly extraverted baseline, but slow return to a highly conscientious baseline can be observed once studying dynamics. Personality is a dynamic and psychological organization that coordinates our experiences and actions towards the health-related behaviour that is tackled during health interventions that is of special interest for all working to change the behaviour patterns of the humans.

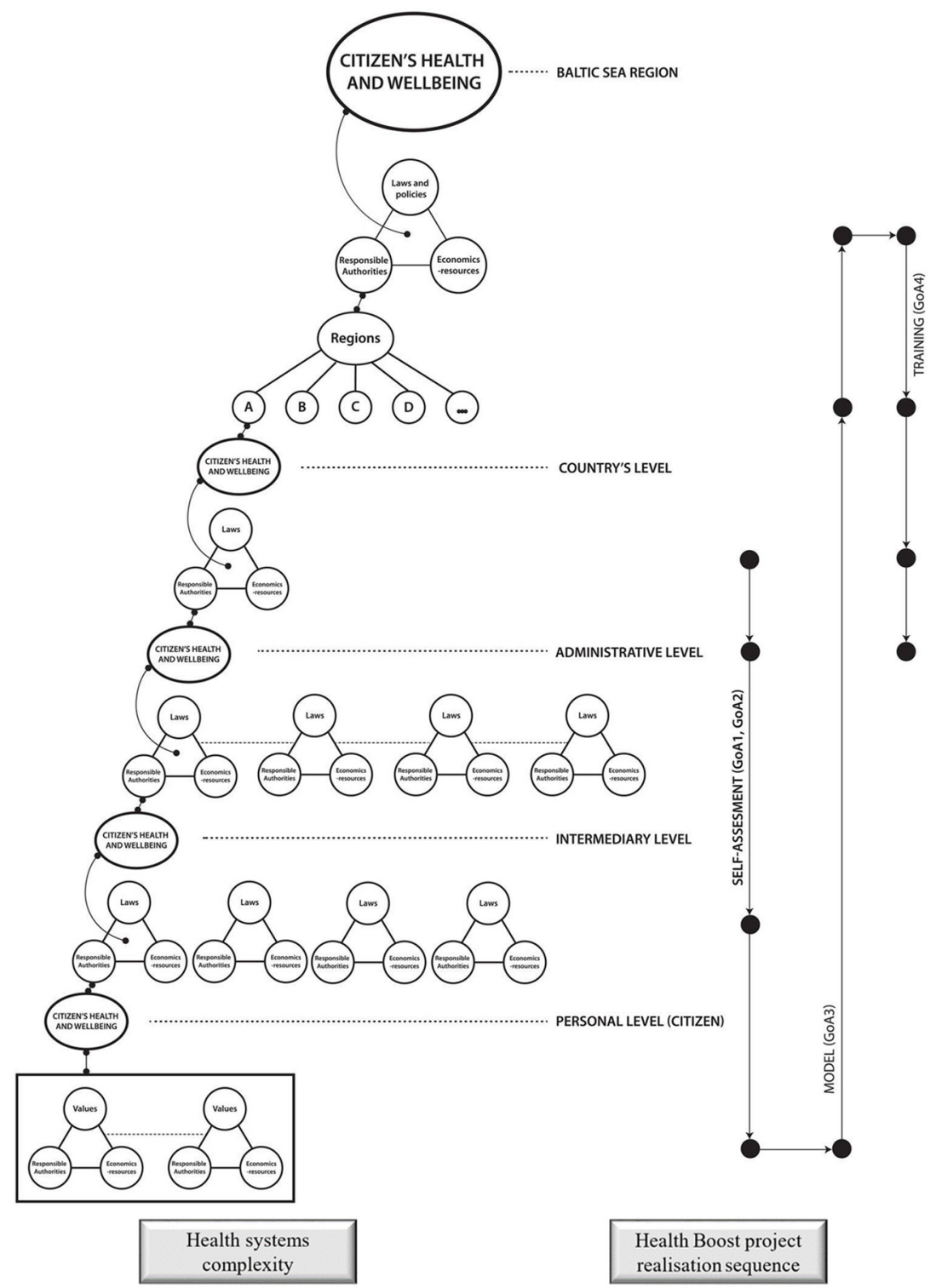

Fig. 2. Complexity of health systems and healthy boost project structure 


\section{How the field of investigation/application of Healthy Boost project could be presented in its main complexity?}

Any health promotion project design directly or indirectly brings us to reality that is described by the properties of complex systems. These properties are of specific importance to be considered during the mapping phase of these interventions. The health care system hierarchy has been created by going from top to bottom. Specifically, the funds are planned for the functioning of such system, institutions that can implement the plans, i.e. absorb funds at various levels of the system hierarchy - regions, cities, municipalities, citizens (Fig. 2 left side). Cooperation in the system between such levels, as well as cooperation between the participating institution at each level, can create opportunities for the implementation of significant healthy boost projects. This can help to implement projects that are difficult or even impossible to implement on a regional or even national scale. By distinguishing common regularities and forming common solutions for the implementation of such projects both funds and regulatory potentials can be saved. This is the purpose of the Healthy Boost EC project (Fig. 2 right side). The objectives of this project include the essential levels of the health system and the peculiarities of the organization of projects at individual levels.

\section{Perspectives and limitations for new approach to the problem}

Before introducing new functionalities in the area of public health, we should consider the existing context (i.e., urban environment) and the formal regularities (i.e., strict, flexible) that mainly determine evolution of such functionalities. Various problem solving in the area of public health can be fostered through the use of technology that consider complex systems theory and its properties as an essential part to solve complex reality-based problems that require holistic perspective.

Realizing that systems of deterministic chaos exist and are necessary in all complex systems, at all fractal levels, we can be sure that prognostic estimates will always be partially erroneous. This is because it depends only on the extent of the mistake. Particularly, we must understand the size of the problem and to apply our proposed solution that are derived from the complex dynamic system theory that encourages to study interlinkages and dynamics between the elements that are determining the possible solutions of the problem.

The main strengths of our study are its novelty, intervention through Healthy Boost realization sequence that is consider complex and dynamic system theories as an essential part of it.

Several limitations should be taken into account once reading the study: a) this is an opinion paper that challenges the traditional rational of public health interventions b) we have not measured the existing interlinkages between basic complexity structure (i.e., regulatory institution, realization activities, financial supply) needed for realization of any health promotion initiative; therefore, combining such scientific ideas together with the real implementation of the project is minimizing the gap between the theory and practice, even though it is not always easy to shrink this wide understanding of the reality to all involved parties of the project. The better understanding of complex system theory is further needed for all individuals working on the lifestyle changes and public health interventions.

\section{Conclusions}

Complex systems properties: interconnections and non-linear dynamics between the system elements, deterministic chaos, fractal levels, harmony or coherence between its system elements, cooperation and competition must be considered. Specifically, it helps to formalize and give meaning to the necessary relations of the "Health Promotion" policy, forming its optimal evolution in society. Under strong and consistent support from both international political arena and scientific community, the recent emergence of an increasing number of good practices from local 
level is present. There seems to be appropriate time to develop and review health promotion activities involving partners from various sectors. The development of effective cooperation and partnerships with the private sector stands as a priority once we take into account the sensitivity of a complex system to environmental multifractality and information transfer between complex networks.

\section{Acknowledgements}

We acknowledge Healthy Boost project as the source of support for all activities leading to preparation of the publication (Healthy Boost Project Number: \#R085 co-financed from the Interreg Baltic Sea Region Programme).

\section{References}

[1] Constitution of the World Health Organization. World Health Organization, Basic documents, 45th ed., Geneva, 2005.

[2] Povlsen L., Borup I. Health Promotion: A developing focus area over the years. Scandinavian Journal of Public Health, Vol. 43, Issue 16, 2015, p. 46-50.

[3] The Ottawa Charter for Health Promotion. World Health Organization, https://www.who.int/healthpromotion/conferences/previous/ottawa/en/.

[4] Milestones in Health Promotion. Statements from Global Conferences. World Health Organization, 2009, https://www.who.int/healthpromotion/Milestones_Health_Promotion_05022010.pdf.

[5] Tremblay M. C., Richard L. Complexity: a potential paradigm for a health promotion discipline. Health Promotion Interventional, Vol. 29, Issue 2, 2011, p. 378-388.

[6] Poland B., Krupa G., Mccall D. Settings for health promotion: an analytic framework to guide intervention design and implementation. Health Promotion Practice, Vol. 10, Issue 4, 2009, p. 505-516.

[7] Xu T., Tomokawa S., Gregorio Jr E. R., Mannava P., Nagai M., Sobel H. School-based interventions to promote adolescent health: A systematic review in low-and middle-income countries of WHO Western Pacific Region. PLoS One, Vol. 15, Issue 3, 2020, e0230046.

[8] Environment and health. Urban health. World Health Organization, http://www.euro.who.int/en/health-topics/environment-and-health/urban-health.

[9] Bulletin of the World Health Organization (BLT). Urbanization and health. World Health Organization, https://www.who.int/bulletin/volumes/88/4/10-010410/en/.

[10] Schulz A. J., Mentz G. B., Sampson N., Ward M., Anderson R., De Majo R., Barbara A., et al. Race and the distribution of social and physical environmental risk: A case example from the Detroit metropolitan area. Du Bois Review: Social Science Research on Race, Vol. 13, Issue 2, 2016, p. 285-304.

[11] Pons Vigués M., Diez È., Morrison J., Salas Nicás S., Hoffmann R., Burstrom B., Van Dijk J. P., et al. Social and health policies or interventions to tackle health inequalities in European cities: a scoping review. BMC Public Health, Vol. 14, Issue 1, 2014, p. 198.

[12] Lecic Tosevski D. Is urban living good for mental health? Current Opinion in Psychiatry, Vol. 32, Issue 3, 2019, p. 204-209.

[13] Economic cost of the health impact of air pollution in Europe: Clean air, health and wealth. World Health Organization Regional Office for Europe, 2015, http://www.euro.who.int/_data/assets/ pdf_file/0004/276772/Economic-cost-health-impact-air-pollution-en.pdf?ua=1.

[14] Burden of Disease from Environmental Noise. Quantification of Healthy Life Years Lost in Europe. World Health Organization Regional Office for Europe, 2011, http://www.euro.who.int I_data/assets/pdf_file/0008/136466/e94888.pdf.

[15] Jackisch J., Sethi D., Mitis F., Szymanski T., Arra A. European Facts and the Global Status Report on Road Safety. World Health Organization Regional Office for Europe, 2015, http://www.euro.who.int/_data/assets/pdf_file/0020/318017/European-country-profile-globalstatus-report-road-safety-2015.pdf?ua $=1$.

[16] Andrea L. Why urbanisation and health? Acta Bio Medica: Atenei Parmensis, Vol. 90, Issue 2, 2019, p. 181-183. 
[17] Penkalla A., Kohler S. Urbanicity and mental health in Europe: a systematic review. European Journal of Mental Health, Vol. 2, 2014, p. 163-177.

[18] Okkels N., Kristiansen C. B., Munk Jørgensen P., Sartorius N. Urban mental health: challenges and perspectives. Current Opinion in Psychiatry, Vol. 31, Issue 3, 2018, p. 258-264.

[19] Galea S., Freudenberg N., Vlahov D. Cities and population health. Social Science and Medicine, Vol. 60, Issue 5, 2005, p. 1017-1033.

[20] Brewster A. L., Yuan C. T., Tan A. X., Tangoren C. G., Curry L. A. Collaboration in health care and social service networks for older adults: association with health care utilization measures. Medical Care, Vol. 57, Issue 5, 2019, p. 327-333.

[21] Amed S., Naylor P. J., Pinkney S., Shea S., Mâsse L. C., Berg S., Collet J. P., et al. Creating a collective impact on childhood obesity: Lessons from the SCOPE initiative. Canadian Journal of Public Health, Vol. 106, Issue 6, 2015, p. 426-433.

[22] Isham G. J., Zimmerman D. J., Kindig D. A., Hornseth G. W. HealthPartners adopts community business model to deepen focus on nonclinical factors of health outcomes. Health Affairs, Vol. 32, Issue 8, 2013, p. 1446-1452.

[23] Health Promotion Glossary. World Health Organization, 1998, https://www.who.int/healthpromotion/HPG/en/

[24] Health promotion. Healthy Cities. World Health Organization, 1998, https://www.who.int/healthpromotion/healthy-cities/en/.

[25] Chapin Iii F. S., Kofinas G. P., Folke C. Principles of Ecosystem Stewardship: Resilience-Based Natural Resource Management in a Changing World. Springer Science \& Business Media, New York, 2009.

[26] Bar Yam Y. Complexity Rising: from Human Beings to Human Civilization, a Complexity Profile, in Encyclopedia of Life Support Systems (EOLSS), Developed under the Auspices of the UNESCO. EOLSS Publishers, Oxford, 2002.

[27] Baranger M. Chaos, Complexity, and Entropy. A physics talk for non-physicists. New England Complex Systems Institute, 2000, http://static1.squarespace.com/static/5b68a4e4a2772c2a206180a1/ t/5bf58df18a922d958275788f/1542819314175/cce.pdf.

[28] Gleick J., Berry M. Chaos-Making a New Science. Viking, New York, 1987.

[29] Remmen G. N., Carroll S. M. Attractor solutions in scalar-field cosmology. Physical Review D, Vol. 88, Issue 8, 2013, p. 083518.

[30] Sircar N. R., Friedman E. A. Financial security and public health: how basic income and cash transfers can promote health. Global Public Health, Vol. 13, Issue 12, 2018, p. 1878-1888.

[31] Arsenijevic J., Groot W., Tambor M., Golinowska S., Sowada C., Pavlova M. A review of health promotion funding for older adults in Europe: a cross-country comparison. BMC Health Services Research, Vol. 16, Issue 5, 2016, p. 288.

[32] Sitko S. J., Kowalska Bobko I., Mokrzycka A., Zabdyr Jamróz M., Domagała A., Magnavita N., Poscia A., et al. Institutional analysis of health promotion for older people in Europe-concept and research tool. BMC Health Services Research, Vol. 16, Issue 5, 2016, p. 327.

[33] Inman D. D., Van Bakergem K. M., Larosa A. C., Garr D. R. Evidence-based health promotion programs for schools and communities. American Journal of Preventive Medicine, Vol. 40, Issue 2, 2011, p. 207-219.

[34] Woynarowska Soldan M. Outcomes evaluation of the school staff health promotion project. Medycyna Pracy, Vol. 67, Issue 2, 2016, p. 187-201.

[35] Lion A., Urhausen A., Delagardelle C., Seil R., Theisen D. Promotion of physical activity for secondary prevention in patients with chronic diseases: the situation in the Grand-Duchy of Luxembourg. Bulletin de la Societe des sciences medicales du Grand-Duche de Luxembourg, Vol. 3, 2014, p. 57-72.

[36] Shanafelt T. D., Noseworthy J. H. Executive leadership and physician well-being: nine organizational strategies to promote engagement and reduce burnout. Mayo Clinic Proceedings, Vol. 92, Issue 1, 2017, p. 129-146.

[37] Otero I., Nieuwenhuijsen M. J., Rojas Rueda D. Health impacts of bike sharing systems in Europe. Environment International, Vol. 115, 2018, p. 387-394.

[38] Holland J. H. Complex Adaptive Systems. Daedalus, Vol. 121, Issue 1, 1992, p. 17-30.

[39] Chan S. Complex Adaptive Systems. ESD. 83 Research Seminar in Engineering Systems, Vol. 31, 2001. 
[40] Sterman J. D. System dynamics modeling: tools for learning in a complex world. California Management Review, Vol. 43, Issue 4, 2001, p. 8-25.

[41] Sturmberg J. P., Picard M., Aron D. C., Bennett J. M., Bircher J., Dehaven M. J., Gijzel S. M. W., et al. Health and disease-emergent states resulting from adaptive social and biological network interactions. A Framework for Debate. Frontiers in medicine, Vol. 6, 2019, p. 59.

[42] Schöner G. Dynamic Thinking: a Primer on Dynamic Field Theory. Oxford University Press, New York, 2016.

[43] Cilliers P., Spurrett D. Complexity and post-modernism: understanding complex systems. South African Journal of Philosophy, Vol. 18, Issue 2, 1999, p. 258-274.

[44] Pruyt E. Small System Dynamics Models for Big Issues: Triple Jump Towards Real-World Complexity. TU Delft Library, Delft, 2013.

[45] Grove J. M. Cities: Managing Densely Settled Social-Ecological Systems. in Principles of Ecosystem Stewardship. Springer, New York, 2009.

[46] Bettencourt L. Complex networks and fundamental urban processes. Mansueto Institute for Urban Innovation Research Paper, Vol. 9, 2019, p. 1-25.

[47] Jagustović R., Zougmoré R. B., Kessler A., Ritsema C. J., Keesstra S., Reynolds M. Contribution of systems thinking and complex adaptive system attributes to sustainable food production: Example from a climate-smart village. Agricultural Systems, Vol. 171, 2019, p. 65-75.

[48] Batty M. Modelling cities as dynamic systems. Nature, Vol. 231, Issue 5303, 1971, p. 425-428.

[49] Borgström S. T., Elmqvist T., Angelstam P., Alfsen Norodom C. Scale mismatches in management of urban landscapes. Ecology and Society, Vol. 11, Issue 2, 2006, p. 16.

[50] Sosnowska J., Kuppens P., De Fruyt F., Hofmans J. A dynamic systems approach to personality: The Personality Dynamics (PersDyn) model. Personality and Individual Differences, Vol. 144, 2019, p. 11-18.

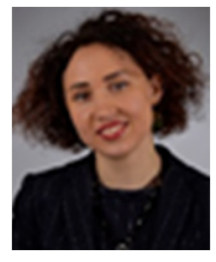

Agnė Slapšinskaitė received a Ph.D. degree in Barcelona University, Barcelona, Spain physical activity, physical education, and sport (Health and quality of life) in 2017. Currently, she is Lecturer and Researcher at LSMU and is a member of Complex Systems in Sport Research Group, Barcelona. Her research stays took place in the Pontifical Catholic University of Rio Grande do Sul, Porto Alegre, Brazil and Johannes Gutenberg University Mainz, Mainz, Germany. In 2019 she won Chinese Scholarship council grand and made a short post-doc in Beijing Sport University, China. Projects: Psychobiology of exercise; Complexity and metabolic risk; BaltCityPrevention and HealthyBoost (Interreg Baltic Sea Region). In this paper is responsible for conceptualization, funding acquisition, methodology, project administration, supervision, visualization, writing - original draft preparation.

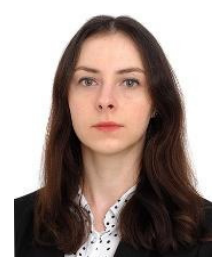

Justina Vaitkevičiūtė received a Ph.D. degree in medical and health sciences, public health from Lithuanian University of Health Sciences, Kaunas, Lithuania, in 2020. Now she works at the Health Research Institute, Faculty of Public Health, Medical Academy, Lithuanian University of Health Sciences. In her work, Justina carries out health monitoring studies, participates in various projects, and writes scientific publications. Her current research interests include children growth and tobacco control. In this paper is responsible for writing - original draft preparation.

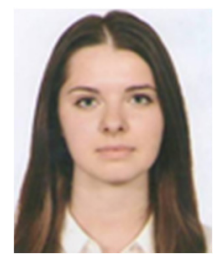

Monika Grincaitè received a Ph.D. degree in medical and health sciences, public health from Lithuanian University of Health Sciences, Kaunas, Lithuania, in 2020. Now she works at the Health Research Institute of Faculty of Public Health of Medical Academy, Lithuanian University of Health Sciences. Her current research interests include child and adolescent health, health promotion. In this paper is responsible for visualization, writing - original draft preparation. 


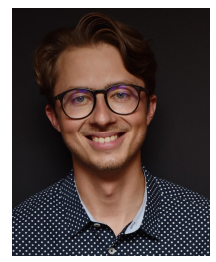

Lukas Galkus is a medical doctor currently working at the Health Research Institute under Lithuanian University of Health Sciences. His professional interests are focused on health topics with special emphasis on psychoactive substances, digital health and healthcare. Currently, Lukas serves as vice-president for youth research at International Youth Health Organization. In this paper is responsible for project administration, writing - review and editing.

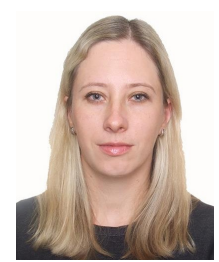

Asta Raskilienė received Ph.D. degree in biomedical sciences, public health from Lithuanian University of Health Sciences, Kaunas, Lithuania, in 2016. Now she works at Health Research Institute, Faculty of Public Health, Medical Academy, Lithuanian University of Health Sciences. Her current research interests include genetics, health behaviour, and risk of noncommunicable diseases. In this paper is responsible for writing - original draft preparation.

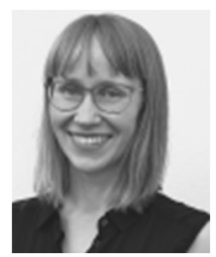

Laura Luukkonen, M.A., works with health promotion projects at the city of Turku, Finland. Her interests lie in the way build environment can support healthy lifestyles and mitigate climate change. In this paper is responsible for writing - original draft preparation.

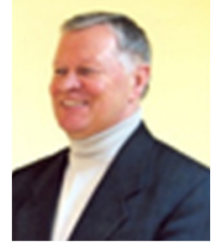

Afonsas Vainoras received $\mathrm{Ph} . \mathrm{D}$. in biomedical sciences, Kaunas Medical Institute in 1980, dr. Habilitatus in 1996, Associate Professor in 2000, Professor in 2003. Now he works at the Health Research Institute of the Faculty of Public Health of Medical Academy, Lithuanian University of Health Sciences. He participates in various projects, and writes scientific publications. His current research interest is development of diagnostic systems in cardiology, complex systems theory application in medicine, public health. In this paper is responsible for conceptualization, methodology, writing - original draft preparation. 